\title{
Dialogic Communication between Teachers and Students as a Condition for Interaction of Subjects of the Higher School Educational Process
}

\author{
Guzel Rinatovna Eremeeva ${ }^{1} \&$ Ismaeva Farida Khamisovna ${ }^{1}$ \\ ${ }^{1}$ Department of Foreign Languages, Institute of International Relations, Kazan Federal University, K Kazan, Russia \\ Correspondence: Guzel Rinatovna Eremeeva, Department of Foreign Languages, Institute of International Relations, \\ Kazan Federal University, K Kazan, Russia.
}

Received: September 9, 2020

Accepted: October 25, 2020

Online Published: October 31, 2020

doi:10.5430/ijhe.v9n8p46

URL: https://doi.org/10.5430/ijhe.v9n8p46

\begin{abstract}
The article is devoted to the issue of educational interaction and cooperation between teachers and students. The purpose of the study is to show the need for dialogic communication in educational activities, form knowledge, and develop educational cooperation skills, allowing students to take an active position in the educational process to help them adapt to interactive learning. The study's methodological base is the technology of sign-contextual learning, the implementation of which involves the use of active teaching methods. The article gives definitions of the concepts "communication", "dialogic communication", "subject". The principles of dialogic communication are highlighted. Experimental work was carried out in pedagogical classes with students of non-pedagogical specialties. Based on the thesaurus, questions, and tasks of the module, "Teaching Methods" were compiled, training was carried out using active methods. Systematic control was achieved by combining different types of work; however, a special role was played by testing, including computer testing. The result of developing communication-dialogue was the emergence of the participants' subjective positions in the dialogue, the formation of their experience of dialogic communication.
\end{abstract}

Keywords: communication, dialogue, cooperation, subject, teacher, student, active methods, interactive learning, sign-contextual learning

\section{Introduction}

The integration of countries in the global educational space requires the modernization of the national model of lifelong education, meeting individuals and society's needs in quality knowledge. The involvement of students in the implementation of their own educational and sociocultural interests makes it necessary to change the attitude to their activities of the main subjects of the educational process - students and teachers. Both teachers and students in the conditions of modern education become active participants in the educational process; their relations acquire a subjective character. They are based on trust, mutual respect, and equality and are realized in the form of a dialogue.

The study aims to show the need for dialogue between teachers and students in educational activities, form knowledge among students, and develop skills and educational cooperation, allowing them to take an active position in the educational process to help adapt to interactive learning.

\section{Methods}

The dialogue between the educational process subjects in our study was achieved by utilizing sign-contextual learning technology. As A.A. Verbitsky defines, "training in which, with the help of the entire system of didactic tools, forms and methods, the subject and social content of a specialist's future professional activity are modeled, and the assimilation of abstract knowledge as sign systems are superimposed on the outline of this activity, is called sign-contextual" (Verbitsky, 1991; Gali et al., 2019). The subject context of professional activity, according to the scientist, is associated with the formation of professional thinking, competent, practical actions of a specialist. The social context presupposes social interaction and communication skills, joint decision-making, and collective mental activity. Therefore, the following principles are embodied in contextual education: 
- sequential modeling in the forms of educational activity of students of holistic content and conditions of the professional activity of specialists

- communication theory and practice

- joint activities

- personality activity

- problems

- unity of training and education

Implementing these principles leads to a change in the traditional forms of study organization at the university. Hence, along with the academic lecture in the technology of sign-contextual learning, a problem-lecture, a lecture-visualization, a lecture together, a lecture with pre-planned errors, a lecture press-conference is used. As A. A. Verbitsky notes, "the described types of lectures mean the rejection of traditional informing students about the "foundations of science" and the implementation of dialogic relations between teachers and students" (Verbitsky, 1991). Following the principles of contextual education, the traditional seminar is also being transformed. Since this form of training organization in context technology is interpreted as the participants' interaction and communication in the educational process, the most appropriate adaptations are the discussion seminar and the round-table seminar (Mostafa \& El-Shokheby, 2020).

Also, the priority is given to technology in a business game in which the student performs a quasi-professional activity that carries the features of both educational and professional activities. Simultaneously, in joint work conditions, each student acquires social interaction skills, a collectivist orientation, value orientations, and attitudes inherent in a specialist.

\section{Results and Discussion}

Communication is a broad and capacious concept in the interpretation of which unity has not been achieved yet. Scientists interpret this process ambiguously, understanding it as activity (Leontiev, 2005; Leontiev, 1983), as relationships (Lomov, 1999), as a multinational phenomenon, including communication, activity, mutual understanding, and mutual influence (Zimnyaya, 1999). We share the point of view of I. A. Zimnyaya, who interprets communication as "a complex, multifaceted process of establishing and developing contacts between people, generated by the need for joint activities and including the exchange of information, the development of a unified interaction strategy, the perception and understanding of another person" (Zimnyaya, 1999).

Characterizing communication, A. A. Leontiev (2005) identifies the following features: contact, orientation, semiotic specialization, and psychological dynamics of the process. The scientist considers contact according to the degree of convergence in the pronounced message's time and space and its perception. Orientation is determined not only by the direction of the exchange of information but also by orientation's social or personal nature. On this basis, the researcher identifies personality-oriented and socially oriented communication. The focus is on changing the characteristics of the interaction of people and changing themselves. The content of the semiotic specialization of communication emphasizes the importance of combining all means - verbal and non-verbal - to increase speech exposure effectiveness. Psychological dynamics are determined by the characteristics of the impact of verbal information. To the listed characteristics, I. A. Zimnyaya (1999) adds two more characteristics of communication.

Representativeness denotes the speaker's subjective representation (teacher or student) in the text, that is, his individual and personal characteristics, cultural level, age, gender, interests, needs, tastes, inclinations, etc. Polyinformativity is the versatility of verbal communication, where all its characteristics (meaningfulness, expressiveness, influence) are realized simultaneously; different levels are reflected (objective, semantic).

Pedagogical communication has a level scheme, which was proposed by J. Janošek (Yanoushek, 1982). At the first level, communication is the transmission and reception of information, its encoding and decoding, and balancing the differences in the initial awareness of the individuals who come into contact. Moreover, in a hidden form, it also includes the participants' mutual relation, which consists of the anticipation of the transmitted information by the listener. At the second level, communication is the mutual transfer and acceptance of participants' values and is directly related to their joint activities to solve a common problem. At the third level, communication is aimed at forming a general assessment of the results achieved, the contributions of individual participants, and it is associated with the collective nature of mutual relations. 
Highlighting the functions of pedagogical communication, we rely on the approach of G. M. Andreeva (Andreeva, 1988). Moreover, we consider it necessary to supplement them with a facilitative function (from the English verb "facilitate" - help, contribute) proposed by C. Rogers (Rogers \& Freiberg, 2002). According to the researcher, the facilitator of communication helps the student express themselves and express their positiveness 0 . The facilitator establishes partnership relations with students, providing them with psychological support during training, and organizes their activities in personality education training. The teacher's interest in the student's success, the benevolent, contact-friendly atmosphere of communication facilitates pedagogical interaction, contributes to the student's self-actualization, and further development. This function is especially relevant in the process of educational activities within the framework of a personality-oriented learning system, as it predetermines the need for dialogical communication.

Thus, in the process of pedagogical communication as a form of educational interaction between teachers and students, there is an exchange of information and the planning and organization of their common activities. In our opinion, the participants' subjective nature in the educational process is manifested, and interaction in such relations takes the form of cooperation.

Defining the subject as "actively acting, cognizing, possessing a person's consciousness, who can show initiative and independence, make and realize a decision, evaluate the consequences of his behavior, change and improve, determine the perspective of his multidimensional life activity" (Dyachenko \& Kandybovich, 1998), we consider that the subjective relations of teachers and students in the process of their joint activities are based on the equality of communication partners, the adoption of another person in their world as values, exclude authoritarian pressure from any part.

The psychological condition for the implementation of "intersubjective communication" in the university's educational process is the neologization of professional communication between students and teachers. It has been proved that communication is the most relevant for organizing productive and personal developing contacts, which, by its standards of organization, can be classified as "dialogic", since it is adequate to the subjective matter of human nature. Dialogic communication is defined as "a form of communication-based on a priori internal acceptance of each other as values in themselves and assuming orientation to the individual uniqueness of every subject" by M. I. Dyachenko and L. A. Kandybovich (Dyachenko \& Kandybovich, 1998). According to scientists, there is a desire for self-education and self-improvement, which is especially important in the educational process.

In the studies of L.A. Petrovskaya (Petrovskaya, 1989), Yu.N. Emelyanov (Emelyanov, 1991), the distinctive features of dialogic communication in the context of its developing capabilities are revealed:

- the equality of the position of the student and the teacher, in which mutual influence is exerted on each other, the ability to take the position of another is formed;

- $\quad$ lack of grades, acceptance of the trainee as he is, respect and trust in him;

- $\quad$ the formation of similar attitudes regarding the same situation;

- the special emotional coloring of communication, sincerity, and naturalness of the manifestation of emotions, mutual penetration into the world of feelings and feelings of each other;

- Communication participants' ability to see, understand, and actively use a wide range of communication tools, including non-verbal ones.

However, knowledge of dialogic communication principles, following them, does not guarantee success in organizing cooperation. According to T.A. Florenskaya (Florenskaya, 1991), success depends on the creative "I" of the teacher on his readiness for "building" relations with students, colleagues, or, as A.I. Titarenko notes, "moral creativity". Such creativity, according to E. N. Shiyanov (Shiyanov, 1991), suggests the construction of a system of appropriate relationships between teachers and students, in which there would be a meaningful dialogue of personalities, the approval of the "I-concept" of each student, all kinds of encouragement of the desire for self-knowledge and self-development. Pedagogically expedient relationships are ones of cooperation that evoke readiness for active complicity, for the responsible and full expression of participants in the pedagogical process (Shiyanov, 1991).

In our opinion, the development of cooperation relations is associated with the voluntary acceptance of a teacher's stimulating role by students. It is manifested in the teacher's desire to learn from the teacher to communicate with him and imitate him. It should be noted that in this case, the determining role is played by the spiritual image of the teacher himself, his professional competence, creative attitude to the work, the ability to collaborate with colleagues. 
It should be noted that students who come to the university already have some ideas about the active teaching methods, a certain experience of joint activities. Moreover, it is not always positive. Therefore, we aspire to help first-year students adapt to interactive learning, update a positive experience, and neutralize joint activities' negative experiences.

In our experimental work, this problem was solved in pedagogical classes. We can mention that this discipline for students of non-pedagogical specialties does not initially cause much interest, although its detailed development is given in the syllabus. Therefore, the course content was focused on the effective use of educational information, interactive teaching methods, technical means of the educational process, and the use of modern educational technologies. Moreover, this discipline's content was implemented through the modules' technologies and sign-contextual learning, which, in our opinion, fits into the modern training system. In accordance with the module technology, the subject's content was built, a rating system for assessing students' knowledge and skills was used. Context technology allowed creating such a learning environment. Such social interaction and communication conditions that the student from the very beginning could take the active position and collaborate with other students and teachers reveal themselves as a subject of activity and communication.

We will show this with the example of the module "Teaching Methods". The thesaurus of this module consists of:

a) such concepts as "teaching method", "heuristic method", "problem method", "game method", "model method"; b) the ability to identify teaching methods by signs, the ability to classify teaching methods, the ability to apply the method in educational activities.

Based on the thesaurus, questions, and tasks of this module are compiled. So, for example, its cognitive part includes the following issues involving the mastery of theoretical knowledge: 1) the nature and characteristics of teaching methods; 2) a system of teaching methods in higher education; 3 ) the main ways to improve teaching methods; 4) the concept of interactive teaching methods. As well as assignments, which are the work with articles and aimed at mastering concepts: a) from the work of M.E. Bershadsky, V. V. Guzeeva "Didactic and psychological foundations of educational technology" (Bershadsky \& Guzeev, 2003) to make extracts on teaching methods. Performing this task, students get acquainted with the classification of teaching methods based on the task approach, master knowledge of programmed, heuristic, problematic, model teaching methods, remember the algorithm for identifying the method; b) prepare a message: "Heuristic methods in the educational process", "Method of problem-based learning and its role in higher education pedagogy", "Project method in higher education". This task is individual in nature; it teaches students to work independently with literature, forms the ability to search for data to reveal the topic of a message, and presents educational material contained in a connected and reasoned manner.

The effectiveness of mastering the necessary knowledge and skills was ensured through the use of contextual technology and interactive teaching aids. In particular, in the pedagogical classes, the discussion method, the brainstorming method, the project method, and the suitable training method were used. They ensured dialogic communication, students' intellectual and personal activity, and a creative atmosphere.

\section{Summary}

Educational games maintained a special place in the process of studying pedagogics Plachova et al., 2019; Abrosimova et al., 2019; Kondrateva et al., 2018; Zarukina, 2010). However, several scientists (Basova, 1999; Traynev, 2004) consider the final stage of higher education to be the most favorable for their application since senior students have a certain level of knowledge and know-how to work independently. From our perspective, educational games must be used in university education from the first year since the game activates the student's mental activity, makes the educational process attractive and exciting, and has a positive emotional effect. The method of the educational game harmoniously fits into the training system, because "the structure of the game as an activity organically includes goal setting, planning, goal realization, as well as analysis of the results in which a person fully realizes himself as a subject" (Selevko, 1998). The motivation for gaming activity is provided by its voluntariness, choice possibilities and competition elements, the satisfaction of the need for self-affirmation, and self-realization.

A freshmen survey, always carried out according to the results of the game. The outcomes revealed that all students of the experimental groups gave an upbeat assessment to educational games, indicating that this method allowed everyone to take an active part and contributed to the formation of knowledge and skills that were useful to them in the process of studying other disciplines.

Systematic control was achieved through a combination of different types of work; however, a unique role was played by testing, including computer testing. We define the tests used for the current and midterm control as a 
system of tasks of increasing difficulty and a specific form, which allows us to evaluate the structure qualitatively and measure the level of knowledge. We use test tasks of three levels: the first level - for recognition; the second level is a reproduction (typical, standard task); the third level is an application (in non-standard conditions). Typically, we give tests in two versions: 1) a battery of tests, that is, a set of tests to verify the activity of only one level; 2) test ladder, that is, a set of tasks that guarantee verification of the content for each module, taking into account all levels of activity.

It should be noted that the attitude of newcomers to testing is ambiguous. On the one hand, they have experience in blank testing because they passed the exams. On the other hand, computer testing arouses their concern, since most students are technically poorly trained. In this regard, when studying the topic "Monitoring and Evaluation of Knowledge", we give students information about the testing method, various types of tests, and teach them the methodology for compiling tests using the interactive training program Hot Potato of the French company EDUSOFT. This helps to activate students' knowledge, encourages, and stimulates the development of students' creative thoughts.

The work is organized in this way while studying the "Pedagogy" course provided, in our opinion, more optimal conditions for the adaptation of freshmen to the educational system at the university. The resulting emotional attitude helped students to engage in the educational process actively. The increased activity of students in the classroom can be judged by the number of types of work performed in the group for one lesson (6-8 compared to 3-5 in the control groups), according to questions asked by students during classes, concerning students' performance of the tasks, the nature of communication with each other during educational activities.

\section{Conclusions}

The result of such developing dialogic communication is the emergence of subjective positions of dialogue participants, the formation of dialogic experience among them, when the participants in joint activities seek to understand exactly the meaning that his communicative partner has in mind, take into account and satisfy his information needs, help the partner to formulate the message. The use of dialogue and communication in the educational process is possible only with the unconditional acceptance of the student's personality, in an atmosphere of goodwill and trust.

Thus, the inclusion of teachers and students in dialogic communication ensures the formation of ideas among students about active teaching methods, the development of communicative skills, and the acquisition of educational cooperation experience, allows to take an active position in the educational process and take responsibility for the results.

\section{Acknowledgements}

The work is performed according to the Russian Government Program of Competitive Growth of Kazan Federal University.

\section{References}

Abrosimova, G., Kondrateva, I., Voronina, E., \& Plotnikova, N. (2019). Blended Learning In University Education. Humanities \& Social Sciences Reviews, 7(6), 06-10. https://doi.org/10.18510/hssr.2019.762

Andreeva, G. M. (1988). Social Psychology: A Textbook. 2nd ed., Ext. and reslave. M.: Publishing House of Moscow State University, $432 \mathrm{p}$.

Basova, N. V. (1999). Pedagogy and practical psychology. Rostov on Don: Felix, 416 p.

Bershadsky, M. E., \& Guzeev, V. V. (2003). Didactic and psychological foundations of educational technology. M.: Center "Pedagogical Search", 256 p.

Dyachenko, M. I., \& Kandybovich, L. A. (1998). Brief psychological dictionary: Personality. education, self-education, profession. Mn.: "Halton", 399 p.

Emelyanov, Yu. N. (1991). Parity dialogue training. L.: Publishing house of Leningrad State University, 210 p.

Florenskaya, T. A. (1991). Dialogue in practical psychology. M., 126 p. 
Gali, G. V., Fakhrutdinova, A. V., \& Gali, A. I. (2019). Methods of Foreign Language Teaching to Linguistically Gifted Students. International Journal of Higher Education, 8(8), 6-10.

Kondrateva, I., Sabirova, D., \& Plotnikova, N. (2018). Subjectivity functions in reflexive and intercultural process of linguistic development. Cypriot Journal of Educational Sciences, 13(4), 529-536. https://doi.org/10.18844/cjes.v13i4.3858

Leontiev, A. A. (2005). Psychology of communication: tutorial. M.: Sense, 368 p.

Leontiev, A. N. (1983). Selected psychological works: In 2 volumes T. II. M.: Pedagogy, 320 p.

Lomov, B. F. (1999). Methodological and theoretical problems of psychology. M.: Nauka, 350 p.

Mostafa, A., \& El-Shokheby, A. (2020). Investigating the Relationship between Cognitive Distortions and Academic Stress for Intermediate School Teachers before and during Work. International Journal of Higher Education, 9(5), 4-11. https://doi.org/10.5430/ijhe.v9n5p46

Petrovskaya, L. A. (1989). Communication competency: socio-pedagogical training. M.: Publishing House of Moscow State University, 216 p.

Plachova, E. A., Kharapudko, E. N., \& Nurmieva, R. R. (2019). Game techniques as a method of the educational process intensification in the teaching a foreign language. Humanities and Social Sciences Reviews, 6, 38-44. https://doi.org/10.18510/hssr.2019.769

Rogers, K., \& Freiberg, J. (2002). Freedom to study. M.: Sense.

Selevko, G. K. (1998). Modern educational technology: textbook. M.: Public education, 256 p.

Shiyanov, E. N. (1991). Humanization of teacher education: state and prospects. Mosk. ped state un-t them. IN AND. Lenin, Stavrop. state ped Inst. Moscow Stavropol, 206 p.

Traynev, I. V. (2004). Constructive pedagogy: tutorial/Under the general ed. V. L. Matrosova. M.: SC Sphere, 320 p.

Verbitsky, A. A. (1991). Active Learning in Higher Education: A Contextual Approach: Method. tutorial. M.: Higher. school, 207 p.

Yanoushek, Y. (1982). Socio-psychological problems of dialogue in the process of cooperation between people. Psycholinguistics abroad: Sb.nauch.tr./ot. Ed. A. A. Leontiev. M.: Nauka, 88-102.

Zarukina, E. V. (2010). Active teaching methods: recommendations for development and application: textbook.-method. tutorial/E. V. Zarukina, N. A. Loginova, M. M. Novik. SPb.: SPbGIEU, 59 p.

Zimnyaya, I. A. (1999). Pedagogical psychology. Textbook for high schools. Ed. second, add., rev. M.: Logos Publishing Corporation, 384 p.

\section{Copyrights}

Copyright for this article is retained by the author(s), with first publication rights granted to the journal.

This is an open-access article distributed under the terms and conditions of the Creative Commons Attribution license (http://creativecommons.org/licenses/by/4.0/). 